\title{
A 100\% Water Mobile Phase HPLC-PDA Analysis of Selected Neonicotinoid Insecticides
}

\author{
Naoto Furusawa
}

Graduate School of Human Life Science, Osaka City University, Osaka 558-8585, Japan

furusawa@life.osaka-cu.ac.jp

\section{ABSTRACT}

This paper describes a reserved-phase HPLC method for detecting frequently-used neonicotinoid insecticides, acetamiprid (ATP) and imidacloprid (ICP), using an isocratic $100 \%$ water mobile phase. Chromatographic separations were performed an Inertsil ${ }^{\circledR}$ WP300 C4 with water mobile phase and a photodiode-array detector. The total run time was $<7 \mathrm{~min}$. The system suitability was well within the international acceptance criteria. The detection limits were $0.013 \mu \mathrm{g}$ $\mathrm{ml}^{-1}$ for ATP and $0.015 \mathrm{\mu g} \mathrm{ml}^{-1}$ for ICP, respectively. A harmless HPLC method for simultaneous detecting ATP and ICP was developed and may be further applied to the quantification in foods.

\section{Indexing terms/Keywords}

Internal harmonized analytical method; Acetamiprid; Imidacloprid; High-Performance Liquid Chromatography; Photo-diode array

\section{Council for Innovative Research}

Peer Review Research Publishing System

\section{Journal: Journal of Advances in Chemistry}

\author{
Vol. 10, No. 9 \\ editorjaconline@gmail.com




\section{INTRODUCTION}

Neonicotinoids are a class of neuro-active/systemic insecticides that act on certain kinds of receptors in the nerve synapse, like nicotine, and are used worldwide as agricultural crop protection and environmental pest management, and control fleas on domestic animals [1]: they are registered in > 120 countries and represented $24 \%$ of the global market for insecticides in 2008 (made up $80 \%$ of all seed treatment sales)[2]. One thing that has made neonicotinoid insecticides popular in pest control is their water solubility, which allows them to be applied to soil and be taken up by plants.

In the early 2000s some kinds of neonicotinoids began to come under increasing scrutiny over potential environmental impacts. The use of neonicotinoids was linked in a range of studies to a number of adverse ecological effects, including honey-bee colony collapse disorder and loss of birds due to reduction in insect populations. Increased scrutiny eventually led to restrictions and bans on the use of different neonicotinoids in several countries [3-7].

In December 2013, two neonicotinoid insecticides, acetamiprid (ATP) and imidacloprid (ICP), may affect the developing human nervous system, disclose the European Food Safety Authority (EFSA). Experts from the Authority propose that some guidance levels for acceptable exposure to the two neonicotinoids be lowered while further research is carried out to provide more reliable data on so-called developmental neurotoxicity [8].

Under the circumstances mentioned above, hard monitoring for the presents of ATP and ICP in all food crops is, therefore, important means to further elucidate the residue situation in foods and to prevent the exposure of consumers to these pesticides.

Depending on the recent expansion and diversification in the international food trade, the development of international harmonized methods to determine chemical residues in foods is essential to guarantee equitable international trade in these foods and ensure food safety for consumers. Whether in industrial nations or developing countries, an international harmonized method for residue monitoring in foods is urgently -needed. The optimal harmonized method must be easyto-use, economical in time and cost, and must cause no harm to the environment and analyst. Although several techniques based on high-performance liquid chromatographic (HPLC) detection have been developed for the monitoring ATP and ICP [9-15], these methods have crucial drawbacks: 1) all of the methods consume large quantities of toxic organic solvents, acetonitrile and/or methanol [16], in the mobile phases. Risk associated with these solvents extend beyond direct implications for the health of humans and wildlife to affect our environment and the ecosystem in which we all reside. Eliminating the use of toxic solvents and reagents is an important goal in terms of environmental conservation, human health and the economy [17,18]; 2) most of the recent methods are based on LC-MS or -MS/MS. The facilities that LC-MS/MS system is available are limited to part of industrial nations because these are hugely expensive, and the methodologies use complex and specific. These are unavailable in a lot of laboratories for routine analysis, particularly in developing countries. No optimal method that satisfies the aforementioned requirements has yet been identified.

As the first examination problem in the establishment of an international harmonized method for the residue monitoring of ATP and ICP, this paper describes an isocratic $100 \%$ water mobile phase HPLC conditions to detect ATP and ICP without the organic solvent/reagent consumption.

\section{Experimental}

\subsection{Chemicals and Reagents}

Standards of acetamiprid (ATP) and imidacloprid (ICP) and distilled water (HPLC grade) were purchased from Wako Pure Chem. Ltd. (Osaka, Japan).

\subsection{Equipment}

The HPLC system, used for method development, included a model PU-980 pump and DG-980-50-degasser (Jasco Corp., Tokyo, Japan) equipped with a model CO-810 column oven (Thosoh Corp., Tokyo, Japan), as well as a model SPD-M10A vP photodiode-array (PDA) detector (Shimadzu Scientific Instruments, Kyoto, Japan).

The following four types of non-polar sorbent columns $\left(5 \mu \mathrm{m} d_{\mathrm{p}} ; 4.6 \mathrm{~mm}\right.$ i.d.; $150 \mathrm{~mm}$ length) for HPLC analysis were used: Inertsil ${ }^{\circledR}$ ODS-4; Inertsil HILIC (diol); Inertsil WP300 C4; Inertsil TMS (C1) (GL Sciences, Tokyo, Japan). Table 1 lists the particle physical specifications.

\subsection{Operating Conditions}

The analytical column was an Inertsil WP300 C4 $(150 \times 4.6 \mathrm{~mm}, 5 \mu \mathrm{m})$ column using an isocratic mobile phase of water at a flow rate of $1.0 \mathrm{ml} \mathrm{min}^{-1}$ at $50^{\circ} \mathrm{C}$. PDA detector was operated at $190-350 \mathrm{~nm}$ : the monitoring wavelengths were adjusted to 245 and $269 \mathrm{~nm}$ which represent maximums for ATP and ICP, respectively (Fig.1). The injection volumes were $10-20 \mu \mathrm{l}$.

\subsection{Preparation of Stock Standards and Working Mixed Solutions}

Stock standard solutions of ATP and ICP were prepared by dissolving each compound in water followed by water to a concentration of $100 \mu \mathrm{g} \mathrm{ml}^{-1}$. Working mixed standard solutions of these two compounds were prepared by suitably diluting the stock solutions with water. These solutions were kept in a refrigerator $\left(5^{\circ} \mathrm{c}\right)$. 


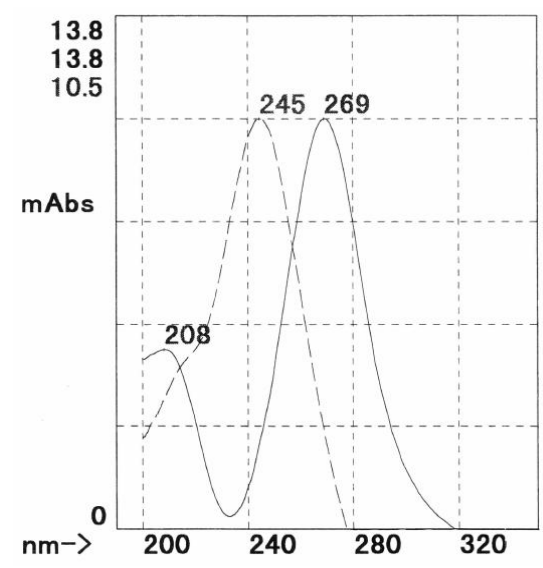

Fig.1: Typical absorption spectra of peaks for ATP (dashed line) and ICP (solid line) standard in the HPLC chromatogram.

\subsection{HPLC Validation}

\subsubsection{Linearity}

The calibration curve was generated by plotting peak areas ranging from 0.025 to $25 \mu \mathrm{g} \mathrm{ml}^{-1}$ versus their concentrations. The linearity was assessed from the linear regression with its correlation coefficient.

\subsubsection{Detection limit}

The detection limit should correspond to the concentration for which the signal-to-noise ratio. The value was defined as the lowest concentration level resulting in a peak area of three times the baseline noise.

\subsubsection{Robustness}

Changes of $\pm 5 \%$ units of the flow rate $\left(1.0 \mathrm{ml} \mathrm{min}^{-1}\right)$ and the column temperature $\left(50^{\circ} \mathrm{C}\right)$ were determined. The effect on the peak areas and the validations in the retention times were evaluated.

\subsubsection{System suitability test}

The HPLC system suitability is an essential parameter of HPLC determination, and it ascertains the strictness of the system used. The suitability was evaluated as the relative standard deviations of peak areas and retention times calculated for 10 replicate injections of a mixed standard solution $\left(0.5 \mu \mathrm{g} \mathrm{ml}^{-1}\right)$.

\section{RESULTS AND DISCUSSION}

\subsection{Optimum HPLC Conditions}

Using four types of non-polar sorbent columns ((a) C18; (b) diol; (c) C4; (d) C1) (Table 1), the author tested to achieve the separation with a $100 \%$ water mobile phase. This study used water as the isocratic mobile phase and examined column temperatures $\geq 25^{\circ} \mathrm{C}$, the flow rates $\geq 0.75 \mathrm{ml} \mathrm{min}^{-1}$, and HPLC retention times $\leq 15$ min (Table 1). Because the HPLC separations were performed serially, the time/run was critical for routine residue monitoring. The short run time not only increased sample throughout for analysis but also affected the method-development time.

The four columns were compared with regard to the separation between ATP and ICP and the sharpness of peaks obtained upon injection of equal amounts. The chromatographic separations within the conditions ranges examined are also presented in Table 1.

The complete separation of the two compounds and their symmetrical peaks were obtained by a Column-(c) and water mobile phase with column temperature of $50^{\circ} \mathrm{C}$ and flow rate of $1.0 \mathrm{ml} \mathrm{min}^{-1}$. Fig.2 displays that the resulting chromatogram obtained from the HPLC. The two target peaks are clearly distinguished at 5.68 and 6.48 min, respectively . The present HPLC-PDA analysis accomplished optimum separation in a short time without the need for a gradient system to improve the separation and pre-column washing after an analysis. 
Table 1. Physical/chemical specifications of the reversed-phase columns ${ }^{a}$ used and chromatographic ATP and ICP separations obtained under the HPLC conditions examined ${ }^{b}$

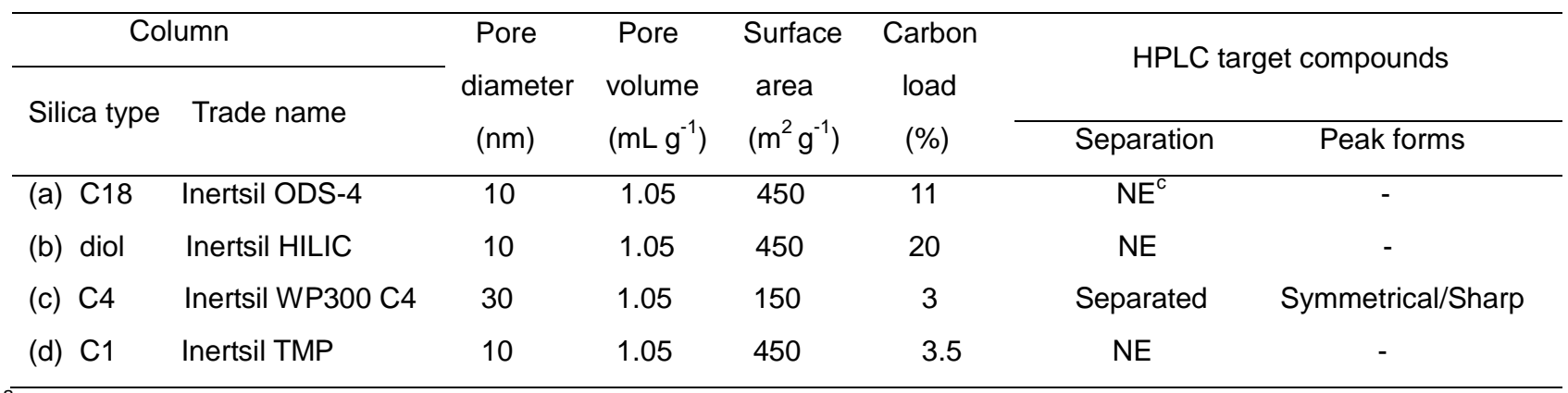

${ }^{a}$ i.d. $=4.6 \mathrm{~mm}$; length $=150 \mathrm{~mm} ; \mathrm{d}_{\mathrm{p}}=5 \mu \mathrm{m}$.

${ }^{\mathrm{b}}$ Isocratic mobile phase of water; flow-rates $\geq 0.75 \mathrm{ml} \mathrm{min}-1$; column temperatures $\geq 25^{\circ} \mathrm{C}$; HPLC retention times $\leq 15 \mathrm{~min}$.

${ }^{\mathrm{c}}$ No ATP and ICP were eluted.

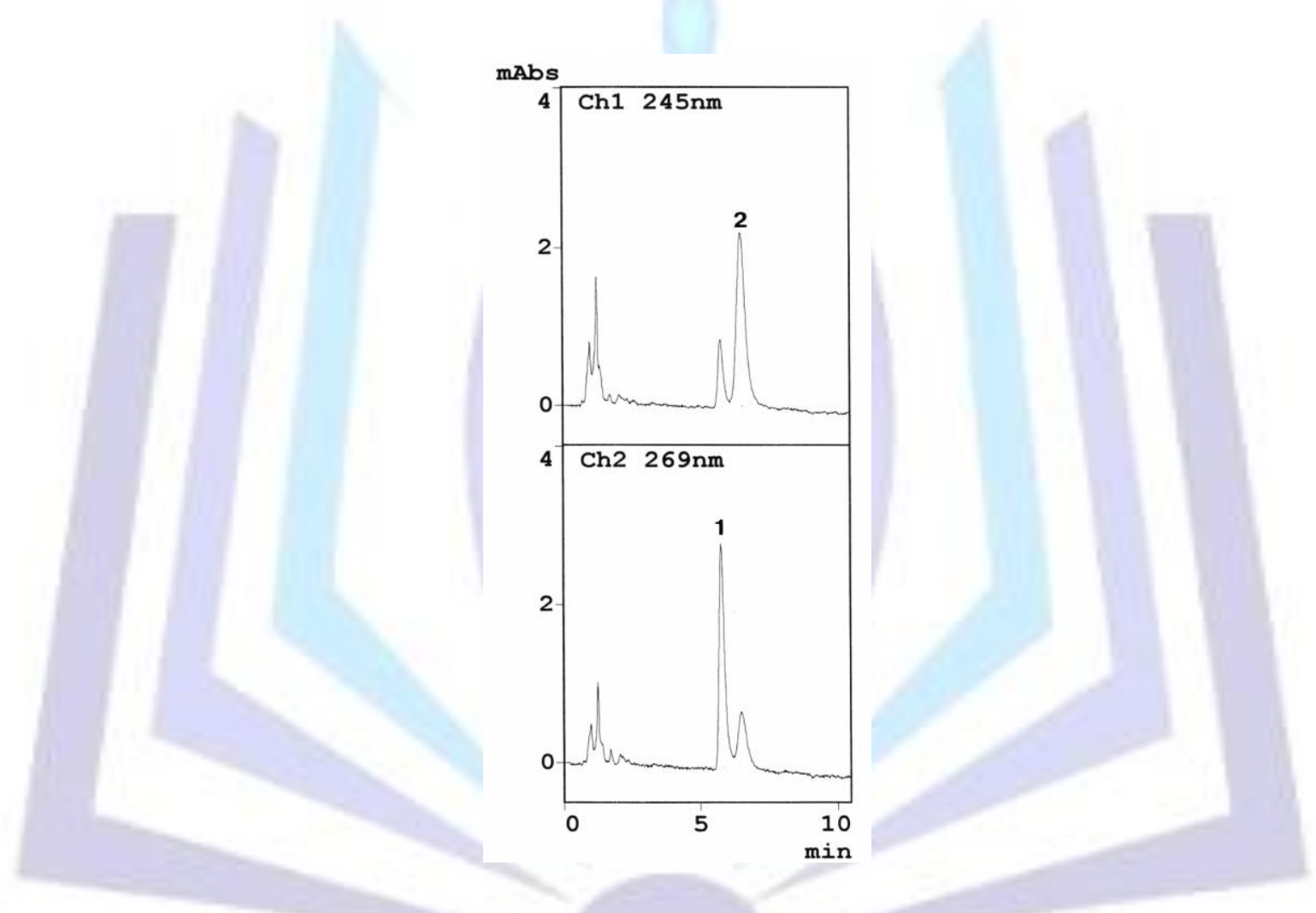

Fig. 2: Typical chromatograms of a standard mixture $(0.5 \mu \mathrm{g} \mathrm{ml}-1)$ obtained from the HPLC system. PDA set at $245 \mathrm{~nm}$ (Ch 1) or $269 \mathrm{~nm}$ (Ch 2). The injection volume was $15 \mu \mathrm{l}$. Peaks, $1=\mathrm{ICP}$ (retention time, $\mathrm{Rt}=5.68 \mathrm{~min}) ; 2=\mathrm{ATP}(\mathrm{Rt}=6.48 \mathrm{~min})$.

\subsection{HPLC Validation}

\subsubsection{Main validation data}

Table 2 summarizes the validation data for the main performance parameters (linearity, range, detection limit, and system suitability). The system suitability values were well within the international acceptance limits [19].

\subsubsection{Robustness}

Changes of $\pm 5 \%$ of the flow rate and the column temperature had no significant effect on the peak areas, whereas the variations in the retention times were obtained with the flow rate and the column temperature. Normal retention times for ATP and ICP were 6.48 and 5.68 min, respectively. At $+5 \%$ the flow rate, the theses retention times were decreased, ranging between 4.1 and $5.4 \%$ and at $-5 \%$, the times were increased ranging between 2.2 and $4.0 \%$. By changing the 
column temperature by $+5 \%$, decreasing retention times obtained were $1.7-4.3 \%$ and at $-5 \%$, the times were increased ranging between 2.1 and $3.0 \%$. During these studies, both target compounds were separated.

Table 2. Chromatographic Method Validation Data

\begin{tabular}{llcc}
\hline & ATP $^{\mathrm{a}}$ & $\mathrm{ICP}^{\mathrm{b}}$ & Acceptance limit $^{\mathrm{c}}$ \\
\hline Linearity $(r)^{\mathrm{a}}$ & 0.9995 & 0.9993 & $\geq 0.999$ \\
Range $\left(\mu \mathrm{g} \mathrm{ml}^{-1}\right)$ & \multicolumn{2}{c}{$0.025-25$} & \\
Detection limit $^{\mathrm{e}}\left(\mu \mathrm{g} \mathrm{ml}^{-1}\right)$ & 0.013 & 0.015 & \\
System suitability : & & & \\
1) Injection repeatability $\left.{ }^{\dagger} \%\right)$ & & & \\
$\quad$ Retention time & 0.22 & 0.48 & $\leq 1$ \\
$\quad$ Peak area & 0.54 & 0.21 & $\leq 1$ \\
2) Tailing factor & 0.75 & 1.04 & $\leq 2$ \\
\hline
\end{tabular}

${ }^{a}$ PDA set at $269 \mathrm{~nm}$. ${ }^{b}$ PDA set at $245 \mathrm{~nm}$. ${ }^{c}$ FDA guidelines [19].

${ }^{d} r$ is the correlation coefficient $(p<0.01)$ for calibration curve. ${ }^{e}$ Detection limit

as the concentration of analyte giving a signal-to-noise ratio $=3$. $^{\mathrm{f}}$ Data as

the relative standard deviations calculated for 10 replicate injections $(10 \mu \mathrm{l})$

of a mixed standard solution $\left(0.5 \mu \mathrm{g} \mathrm{ml}^{-1}\right.$ of ATP and ICP, respectively).

\section{CONCLUSION}

In the present paper, a HPLC-PDA method for detecting ATP and ICP using an isocratic $100 \%$ water mobile phase has been successfully established. The water mobile phase method is harmlessness to the environment and to humans and has a short run time and high system suitability. The HPLC system may be proposed as an international harmonized method for detecting ATP and ICP. For the quantification in various foods, the proposed HPLC method will be applicable enough by performing a suitable sample preparation technique.

\section{REFERENCES}

[1] Elbert, A., Haas, M., Springer, B., Thielert, W., and Nauen, R. 2008. Applied aspects of neonicotinoid uses in crop protection. Pest Manag. Sci. 64 (Nov. 2008), 1099-1105.

[2] Jeschke, P., Ralf Nauen, R., Schindler, M., and Elbert, A. 2011. Overview of the Status and Global Strategy for Neonicotinoids. J. Agri. Food Chem. 59 (2011), 2897-2908.

[3] Cressey, D. 2013. "Europe debates risk to bees". Nature 496 (2013): 408.

[4] Current Opinion in Environmental Sustainability. 2013.5 (2013), 3-4, 293-305.

[5] European Commission 2013: Regulation (EU) No 485/2013, 2013. (http://eur-lex.europa.eu/LexUriServ/ LexUriServ. do?uri=OJ:L:2013:139:0012:0026:EN:PDF)

[6] European Commission 2013. Bees \& Pesticides: Commission goes ahead with plan to better protect bees. 30 May 2013. (http://ec.europa.eu/food/archive/animal/liveanimals/bees/neonicotinoids_en.htm)

[7] Charlotte McDonald-Gibson 2013. "'Victory for bees' as European Union bans neonicotinoid pesticides blamed for destroying bee population". The Independent, Retrieved 1 May 2013. (http://www.independent.co.uk/environment /nature/victory-for-bees-as-european-union-bans-neonicotinoid-pesticides-blamed-for-destroying-bee-population8595408.html)

[8] European Food Safety Authority (EFSA) 2013. EFSA assesses potential link between two neonicotinoids and $\begin{array}{llllll}\text { developmental } & \text { neurotoxicity. } & \text { Press } & \text { release } & 17 & \text { December }\end{array}$ (http://www.efsa.europa.eu/en/press/news/131217.htm)

[9] Chen, M., Collins, E.M., Tao, L., and Lu, C.S. 2013. Simultaneous determination of residues in pollen and highfructose corn syrup from eight neonicotinoid insecticides by liquid chromatography-tandem mass spectrometry. Anal. Bioanal. Chem. 405 (Nov. 2013), 9251-9264.

[10] Xiao, Z.M., Yang, Y.X., Li, Y., Fan, X., and Ding, S.Y. 2013. Determination of neonicotinoid insecticides residues in eels using subcritical water extraction and ultra-performance liquid chromatography-tandem mass spectrometry. Anal. Chim. Acta 777 (Mer. 2013), 32-40. 
[11] Jovanov, P., Guzsvany, V., Franko, M., Lazic, S., Sakac, M., Saric, B., and Banjac, V. 2013. Multi-residue method for determination of selected neonicotinoid insecticides in honey using optimized dispersive liquid-liquid microextraction combined with liquid chromatography-tandem mass spectrometry. Talanta 111 (Jul. 2013), 125-133.

[12] Xie, W., Han, C., Qian, Y., Ding, H.Y., Chen, X.M., and Xi, Y.J. 2011. Determination of neonicotinoid pesticides residues in agricultural samples by solid-phase extraction combined with liquid chromatography-tandem mass spectrometry. J. Chromatogr. A 1218 (Jul. 2011), 4426-4433.

[13] Seccia, S., Fidente, P., Montesano, D., and Morrica, P. 2008. Determination of neonicotinoid insecticides residues in bovine milk samples by solid-phase extraction clean-up and liquid chromatography with diode-array detection. J. Chromatogr. A 1214 (Dec. 2008), 115-120.

[14] Di Muccio, A., Fidente, P., Barbini, D.A., Dommarco, R., Seccia, S., and Morrica, P. J. 2006. Application of solidphase extraction and liquid chromatography-mass spectrometry to the determination of neonicotinoid pesticide residues in fruit and vegetables. J. Chromatogr. A 1108 (Mar. 2006), 1-6.

[15] Ferrer, I., Thurman, E.M ., Fernandez-Alba, A.R. 2005. Quantitation and accurate mass analysis of pesticides in vegetables by LC/TOF-MS. Anal. Chem. 77 (May. 2005), 2818-2825.

[16] EU classification (The Dangerous Substances Directive 67/548/EEC): Council Directive 67/548/EEC of 27 June 1967 on the approximation of laws, regulations and administrative provisions relating to the classification, packaging and labelling of dangerous substances.

[17] Anastas, P.T., and Warner, J.C. 1998. Green Chemistry: Theory and Practice; Oxford University Press: Oxford, United Kingdom.

[18] Yoshimura, T., Nishinomiya, T., Homda, Y., and Murabayashi, M. 2001. Green Chemistry : Aim for the Zero EmissionChemicals, Sankyo Publishing Co. Ltd. Press, Tokyo, Japan.

[19] FDA 1994. Reviewer Guidance, Validation of Chromatographic Methods, Center for Drug Evaluation and Research (CFDER) 1994. 